\title{
CHILDHOOD EYE DISEASES IN SOUTHWESTERN NIGERIA: A TERTIARY HOSPITAL STUDY
}

\author{
Oluwatoyin Helen Onakpoya, ${ }^{\mathrm{I}, \mathrm{II}}$ Adenike Odunmorayo Adeoye ${ }^{\mathrm{I}}$
}

doi: 10.1590/S1807-59322009001000003

Onakpoya OH, Adeoye AO. Childhood eye diseases in southwestern Nigeria: a tertiary hospital study. Clinics. 2009;64(10): 947-51.

BACKGROUND: Eye diseases are important cause of medical consultation in children, with the spectrum varying in different localities. This study aimed to determine the spectrum of childhood eye diseases in a tertiary hospital serving rural and semi-rural communities.

METHODS: We conducted a retrospective review of all patients less than 15 years old who presented to the eye clinic of Wesley Guild Hospital Ilesa, Nigeria between January 2001 and December 2006. Data on age at presentation, age at onset of disease, sex and diagnosis were collected and analyzed using SPSS. A $p$ value less than 0.05 was considered statistically significant.

RESULTS: We evaluated the reports of 286 children, with a male:female ratio of 1:1.1. Children aged 11-15 years made up the largest group ( $p=0.013)$. Ocular trauma (21.7\%), allergic conjunctivitis (17.8\%), infections of the eye and its adnexa (15.4\%) and refractive errors $(14.3 \%)$ were the most common conditions. Ocular injury was more common in males $(p=0.002)$ and children aged 6-10 years, and $87.1 \%$ of these cases were a closed globe injury. Infections were seen more commonly among females and children aged $0-5$ years, with keratitis representing $40.9 \%$ of these cases. Congenital eye disease represented $13.3 \%$ of childhood eye diseases.

CONCLUSION: The prevalent childhood eye diseases recorded here can lead to absenteeism from school and are potentially blinding. Health education aimed at the prevention of ocular trauma and prompt presentation for the management of other eye diseases should be encouraged.

KEYWORDS: Allergic conjunctivitis; Pediatric ocular disorders; Nigeria; Ocular trauma; Refractive errors.

\section{INTRODUCTION}

Eye diseases in children are important cause of medical consultation. ${ }^{1}$ Children should receive prompt and proper eye care in order to avoid vision problems and eye morbidities, which could affect their learning ability, personality and adjustment in school., ${ }^{2,3}$ Vision is an important requirement for learning and communication. ${ }^{4}$ Childhood blindness is second only to cataracts in terms of "blind years." Complaints necessitating eye care consultation can originate

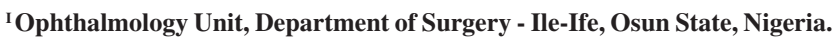
II Department of Anatomy and Cell Biology, Obafemi Awolowo University Ile Ife, Osun State, Nigeria.

Email: uvtoyin2@yahoo.co.uk / ufuoma@oauife.edu.ng

Tel.: + 2348037194945

Received for publication on May 05, 2009

Accepted for publication on July 03, 2009 from the child, parents or even teachers. ${ }^{6}$ The spectrum of ocular problems varies from country to country and even from region to region in the same country. ${ }^{2}$ In the United States, strabismus, amblyopia and optical problems impacting visual acuity are the most common ocular problems seen among school-aged children. ${ }^{7}$ Refractive errors $(25.7 \%)$, vernal conjunctivitis $(25.3 \%)$, eye injuries $(13.3 \%)$ and corneal inflammation $(12.5 \%)$ were the leading causes of childhood eye morbidity reported 12 years ago in in Ibadan, Nigeria. ${ }^{8}$ Meanwhile, trachoma (33.7\%), refractive errors $(6.3 \%)$ and non-trachomatous conjunctivitis (5.9\%) were the most common childhood eye disorders reported in Ethiopia. ${ }^{9}$

Data on the pattern of presentation of childhood eye diseases serve as useful template for planning eye care for children in a given region. Children in rural communities may be involved in agrarian activities, which could impact 
their health. This study was conducted to determine the frequency and spectrum of childhood eye disorders presenting to the eye clinic of Wesley Guild Hospital, Ilesa. These findings will be useful for pediatric ophthalmic care planning and could also serve as a baseline for the development of a pediatric ophthalmology subspecialty in the tertiary hospital.

\section{METHODS}

All new patients aged 15 years and younger who presented to the eye clinic of the Wesley Guild Hospital (WGH), Ilesa, Nigeria between January 2001 and December 2006 were retrospectively reviewed. Children who presented for a medical check-up and had no eye disorders were excluded from the study. The eye clinic of WGH, Ilesa serves as a referral center for the rural and semirural communities of Osun, along with the neighboring communities, Ekiti and Ondo states in southwestern Nigeria. It also provides primary and secondary eye care services to self-reporting patients. At the first visit, all patients had a full ophthalmic evaluation carried out by a consultant ophthalmologist. Tests were conducted to elicit a diagnosis, and management commenced as required. Subsequently, patients were seen by resident ophthalmologists under the supervision of the consultant. Consultations to pediatricians and other specialists were made when necessary. An examination under anesthesia was carried out to confirm a diagnosis when required.

The age at presentation, sex, clinical diagnosis and age at onset of symptoms were determined from medical records. The clinical diagnosis was grouped as appropriate; diseases present at birth but not due to birth circumstances were considered congenital. Patients were grouped by age into a preschool (0-5 years), school-age (6-10 years) or older children (11-15 years) group.

Data were stored and analyzed using the Statistical Package of the Social Sciences software and are presented as simple frequencies or cross-tabulations. A chi-squared test was used to compare variables and a $p$ value less than 0.05 was considered statistically significant.

\section{RESULTS}

We evaluated 286 records of children who were seen in the eye clinic during the study period, constituting $14.3 \%$ of all new patients seen. There were $138(48.3 \%)$ males and $148(51.7 \%)$ females, resulting in a male:female ratio of 1:1.1. Figure 1 shows the age group and sex distribution of the children seen, with a female preponderance in the 11-15 years age group. The highest frequency of consultation was

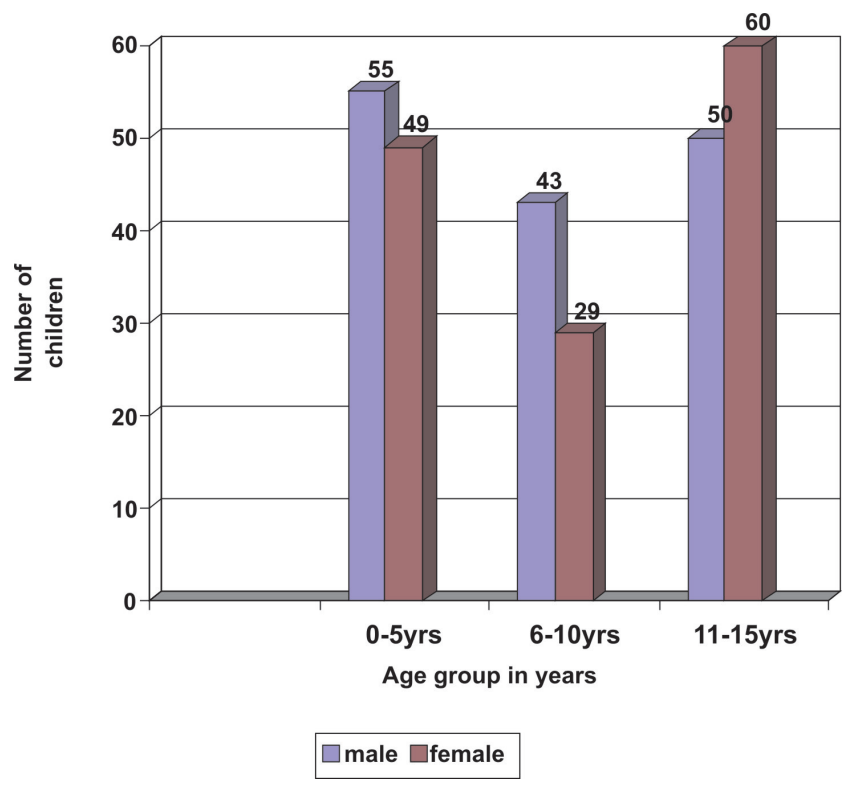

Figure 1 - Age group and sex distribution of children

recorded among older children, constituting $38.5 \%$ of the patients $(p=0.013)$.

Ocular injuries were the most common disorders seen (21.7\%), followed by allergic conjunctivitis (17.8\%), infection of the eye and its adnexa (15.4\%) and refractive errors (14.3\%). Figure 2 shows the spectrum and frequency of eye morbidities seen. Uveitis was seen in six children, and a 15-year-old child presented with pterygium.

The frequency and pattern of eye diseases varied across the three age groups (Table 1). The difference in presentation by age group was more prominent and statistically significant among children with refractive errors

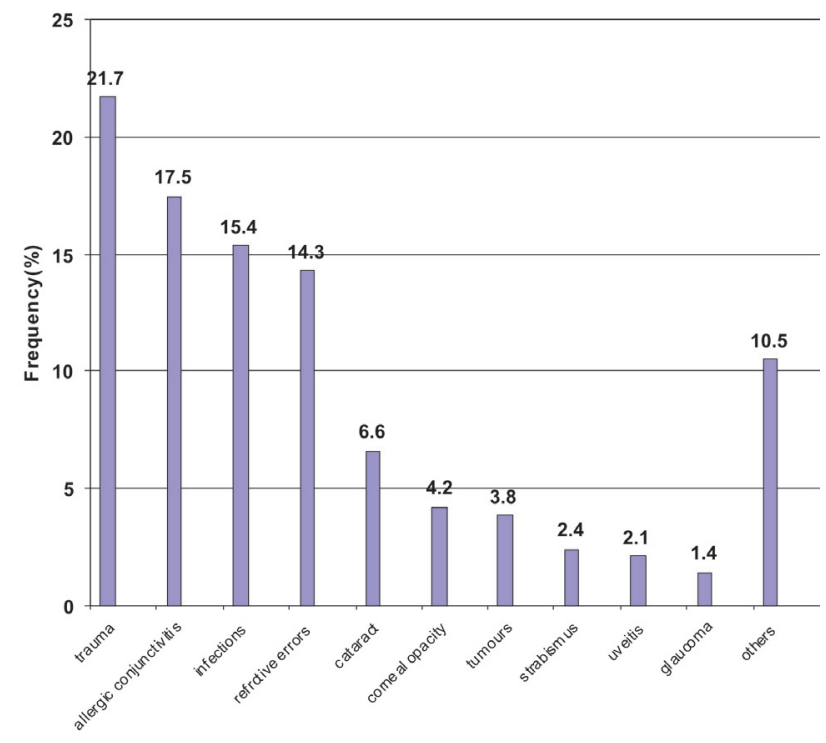

Figure 2 - Spectrum of childhood eye disorders 
Table 1 - Distribution of childhood eye diseases across age groups

\begin{tabular}{lcccc}
\hline Diagnosis & \multicolumn{4}{c}{ Age group (years) } \\
\cline { 2 - 5 } & $\mathbf{0 - 5}(\boldsymbol{\%})$ & $\mathbf{6 - 1 0}(\boldsymbol{\%})$ & $\mathbf{1 1 - 1 5 ( \% )}$ & Total(\%) \\
\hline Ocular trauma & $16(25.8)$ & $26(41.9)$ & $20(32.3)$ & $62(21.7)$ \\
$\begin{array}{l}\text { Allergic } \\
\text { conjunctivitis }\end{array}$ & $12(24)$ & $12(24)$ & $26(52)$ & $50(17.5)$ \\
$\begin{array}{l}\text { Infections } \\
\text { of eye and }\end{array}$ & $31(70.5)$ & $5(11.4)$ & $8(18.2)$ & $44(15.4)$ \\
adnexa & & & & \\
$\begin{array}{l}\text { Refractive } \\
\text { errors }\end{array}$ & $2(4.9)$ & $10(24.4)$ & $29(70.7)$ & $41(14.3)$ \\
Cataract & $7(36.8)$ & $8(42.1)$ & $4(21.1)$ & $19(6.6)$ \\
Corneal & $4(33.3)$ & $4(33.3)$ & $4(33.3)$ & $12(4.2)$ \\
opacity & & & & \\
Tumors & $5(45.5)$ & $2(18.2)$ & $4(36.3)$ & $11(3.8)$ \\
Strabismus & $4(57.1)$ & $1(14.3)$ & $2(28.6)$ & $7(2.4)$ \\
Uveitis & $1(16.7)$ & - & $5(83.3)$ & $6(2.1)$ \\
Glaucoma & $3(75)$ & - & $1(25)$ & $4(1.4)$ \\
Others & $19(63.3)$ & $4(13.3)$ & $7(23.9)$ & $30(10.5)$ \\
\hline Total & $\mathbf{1 0 4}(\mathbf{3 6 . 4})$ & $\mathbf{7 2 ( 2 5 . 2 )}$ & $\mathbf{1 1 0}(\mathbf{3 8 . 4})$ & $\mathbf{2 8 6 ( 1 0 0 )}$ \\
\hline
\end{tabular}

and infections. There were $29(70.7 \%)$ cases of refractive errors among older children $(p<0.001)$, while infection of the eye adnexa was recorded more frequently (70.5\%) among preschool children $(p<0.001)$.

Among the children with ocular injury, 43 (69.4\%) were boys $(p=0.002)$. Ocular trauma was recorded more often among school-aged children, constituting $41.9 \%$ of all traumatic eye disorders. Eye injury was unilateral in all cases. Table 2 shows the pattern of ocular trauma seen in the 62 children, with the majority $(87.1 \%)$ being closed globe injuries. Traumatic hyphema was recorded in $5(11.4 \%)$ of the 44 children who presented with a contusive eye injury.

The incidence of allergic conjunctivitis was higher in older children, with $52 \%$ of the cases recorded in children

Table 2 - Pattern of ocular trauma in 62 children

\begin{tabular}{llc}
\hline Type of Injury & & Frequency (\%) \\
\hline Closed globe injury & - contusion & $44(71)$ \\
& $\begin{array}{l}\text { - superficial corneal } \\
\text { foreign body }\end{array}$ & $9(14.5)$ \\
& $\begin{array}{l}\text {-superior tarsal foreign } \\
\text { body }\end{array}$ & $1(1.6)$ \\
& $\begin{array}{l}\text {-penetrating } \\
\text {-periorbital soft tissue }\end{array}$ & $6(9.7)$ \\
Others & injury & $1(1.6)$ \\
& -chemical eye injury & $1(1.6)$ \\
\hline Total & & $\mathbf{6 2}(\mathbf{1 0 0})$ \\
\hline
\end{tabular}

aged 11-15 years $(p=0.02)$. No gender differences were observed. Among the children who presented with infections, $27(61.4 \%)$ were female $(p=0.132)$. Anatomically, corneal infections accounted for $40.9 \%$ of all cases of childhood eye and adnexa infections, $33.3 \%$ of which were related to measles (Figure 3). All cases of corneal infection were in children aged 5 years and younger. Tumors accounted for $3.8 \%$ of the childhood eye diseases during the study period, with three cases $(27.3 \%)$ of retinoblastoma, three cases $(27.3 \%)$ of dermoids, two cases $(18.2 \%)$ of Burkitt's lymphoma and one case $(9.1 \%)$ each of a orbital rhabdomyosarcoma, a conjunctival mass and an eye lid mass.

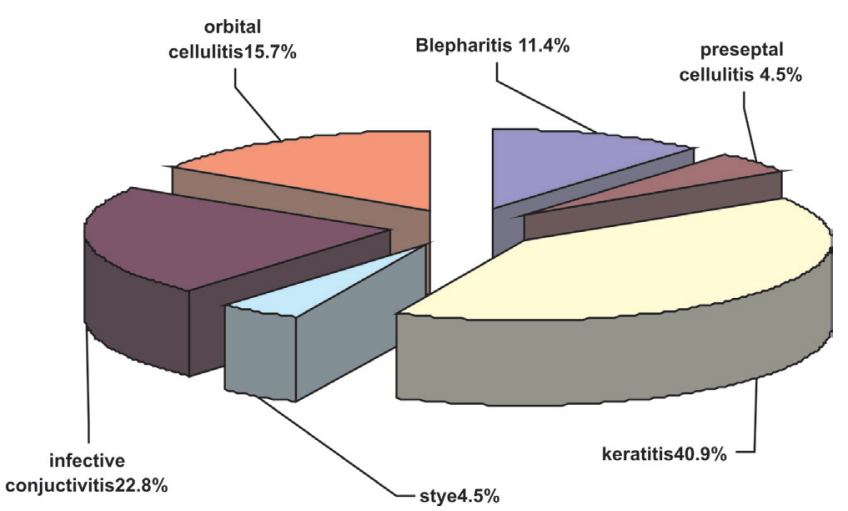

Figure 3 - Childhood infections of the eye and adnexa

Almost three-quarters $(73.2 \%)$ of the children with refractive errors were female $(p=0.003)$. Congenital eye diseases were found in 38 of the $286(13.3 \%)$ children, of which $76.3 \%$ presented as preschool children. Table 3 shows the pattern of congenital eye diseases seen, with congenital cataract and strabismus occurring more frequently.

Table 3 - Distribution of congenital ocular disorders among age groups

\begin{tabular}{lcccc}
\hline \multirow{2}{*}{$\begin{array}{l}\text { Congenital eye } \\
\text { disease }\end{array}$} & \multicolumn{5}{c}{ number } \\
\cline { 2 - 5 } & $\mathbf{0 - 5}$ yrs & $\mathbf{6 - 1 0}$ yrs & $\mathbf{1 1 - 1 5}$ yrs & Total (\%) \\
\hline Cataract & 7 & 2 & - & $9(23.7)$ \\
Strabismus & 4 & - & 2 & $6(15.9)$ \\
Glaucoma & 3 & - & - & $3(7.9)$ \\
Ptosis & 2 & 1 & - & $3(7.9)$ \\
Microphthalmia & 1 & 1 & 1 & $3(7.9)$ \\
Dacryostenosis & 2 & - & - & $2(5.2)$ \\
Presumed Leber's & 2 & - & - & $2(5.2)$ \\
amaurosis & & & & \\
Dermoid cyst & 1 & - & 1 & $2(5.2)$ \\
Eye lid eversion & 2 & - & - & $2(5.2)$ \\
$*$ Others & 5 & - & 1 & $6(15.9)$ \\
\hline Total & $\mathbf{2 9}$ & $\mathbf{4}$ & $\mathbf{5}$ & $\mathbf{3 8}(\mathbf{1 0 0})$ \\
\hline
\end{tabular}

* Others are made up of one patient each with macrophthalmia, corneal opacity, persistent hyperplastic primary vitreous, oculocutaneous albinism, ocular albinism and lateral canthal skin tag. 


\section{DISCUSSION}

Children have unique problems in terms of ocular morbidities, not only due to their inability to articulate their problems, but also because of the potential to develop amblyopia in the event of visual impairment. ${ }^{4}$ The higher frequency of consultations in older children in this study may be due to their ability to be more articulate about their problems, while the chronicity of some of the eye disorders may also be a contributing factor. This frequency differs from a similar study reporting a higher incidence of consultation in children younger than 5 years of age. A difference in the spectrum and incidence of childhood eye disorders may account for this. ${ }^{10}$

Ocular trauma was the most common morbidity seen in this study, which is different from other reports in which pediatric eye injuries were the third ${ }^{8,10,11}$ or fourth ${ }^{12}$ most common disorder reported. In India ${ }^{2}$ and other regions in Nigeria ${ }^{10-13}$, allergic conjunctivitis has been the most frequently reported childhood eye disease, while refractive error has been more frequently reported in Ibadan. ${ }^{8}$ The reason for such a high frequency of pediatric eye injuries in this environment is not clear. The largely agrarian nature of the communities may predispose the children to injuries from twigs and farming activities. Further study of predisposing factors to eye injuries in children in this region is needed, given that the identification of the causes of injury helps in developing effective preventive measures. ${ }^{16}$ Eye injuries remain a major cause of unilateral visual impairment worldwide ${ }^{17}$ and a common cause of noncongenital unilateral blindness. ${ }^{18}$ Children are particularly at risk of ocular injury due to their decreased ability to detect and avoid potential hazards. ${ }^{16,19}$ Most childhood eye injuries are sustained during unsupervised play and domestic activities..$^{20-23}$ The male preponderance reported here has been previously described. ${ }^{19-23}$ The higher incidence of injuries reported among school children is also similar to other studies. ${ }^{16,21,24}$ This group represents an independent and adventurous age group, making them more vulnerable. Closed globe injury was most common, consistent with several previous studies, ${ }^{2,16,23}$ although a study by Kaduna found that open globe injuries were more common. ${ }^{21}$ The challenge of managing childhood eye injuries in this environment is enormous. Considerations range from late presentation to eye care centers to a lack of facilities, the low socioeconomic status of the children involved, the special care required during examination, postoperative management and the risk of amblyopia. ${ }^{10,16,21,23}$ Prevention of ocular trauma in children remains a priority in order to reduce ocular morbidity. ${ }^{16}$ This will involve the adequate education of children, parents and teachers to ensure adequate supervision at play and avoidance of risky chores.

Previous reports of allergic conjunctivitis as the most common surface disorder in children ${ }^{1,10-13,25}$ are corroborated by this study. Communities with largely agrarian labor and a dusty environment may be contributory. ${ }^{5,10}$ Moreover, rural living is a risk factor for the development of chronic allergic conjunctivitis in children. ${ }^{26} \mathrm{~A}$ slight female prevalence was noted in this study, which differed from other reports that demonstrated a male prevalence. ${ }^{26,27}$ The higher incidence noted among older children may be related to factors affecting late presentation to an eye care facility for a chronic recurrent disease rather than the actual prevalence of the disease. Allergic conjunctivitis is a leading cause of absenteeism from school due to its discomfort, chronicity and recurrence. ${ }^{25}$ Adequate management can bring symptoms under control and prevent potentially blinding complications, loss of concentration and absenteeism from school. ${ }^{14}$

Ocular infections are preventable but challenging causes of blindness, particularly in children given the number of blind years involved. Corneal infections constituted more than one-third of the infections of the eye and adnexa in this study and are particularly notorious for causing blinding corneal scars. Corneal scarring accounts for $75 \%$ of childhood blindness in Africa, with half of these cases involving a history of measles shortly before blindness. ${ }^{18,26}$ More recent reports have credited the Expanded Programme on Immunization for a downward trend in the incidence of measles infection and associated ocular morbidities in Nigeria. ${ }^{1,10}$ Total eradication is desired, however, as $33 \%$ of childhood keratitis in this study was due to measles; that is, they involved a history of recent measles before the onset of eye disease. Preschool children were more likely to present with infections of the eye and adnexa in this study, and this may be related to the higher risk of measles infection in the same age group. While efforts to establish corneal banking services in Nigeria are ongoing, prevention and prompt treatment of corneal infections is essential.

Refractive errors affect childhood development, given that $80 \%$ of learning in children is sight-dependent. ${ }^{28}$ In the absence of regular preschool or school eye-screening for refractive errors, many children with refractive errors go unnoticed. The incidence of refractive errors in this study may have been underestimated since it was a hospital-based study, and only children with obvious complaints would be detected. Moreover, the higher incidence reported in older children could be due to better articulation and detection of visual problems by older children, suggesting a lack of detection by parents and teachers at younger ages. The statistically significant female prevalence is similar to a previous report, suggesting that young females tend to report visual problems more than males. ${ }^{17}$ School health services that regularly screen 
for refractive errors and refer affected children for refractive services can prevent poor performance in school and the development of amblyopia. ${ }^{3,10,14}$ The belief that eyeglass use in children further destroys the ey $\mathrm{e}^{10}$ must be changed via health education in order to ensure early presentation and improve the use of existing refractive services.

Nine $(47.4 \%)$ childhood cataract cases in this study were congenital. Childhood cataracts are not managed as a simply smaller version of adult cataracts and pose different challenges including preoperative assessment, general anesthesia, correction of aphakia, postoperative care and follow up for posterior capsular opacification or glaucoma. Many patients are poor and cannot afford the available cataract surgical services, especially intraocular lens implantation, which is the best option for aphakic correction in most children to reduce the incidence of post-operative amblyopia. ${ }^{10,21}$

In conclusion, the most common causes of childhood ocular morbidity in this study were injuries, allergic conjunctivitis, infections and refractive errors. These disorders require specialist eye care services for proper management given that they lead to absenteeism from school and are potentially blinding. Appropriate health education needs to be disseminated for the prevention of childhood eye injuries, as well as early presentation of children to eye care centers for the treatment of eye disorders.

\section{REFERENCES}

1. Nwosu SNN. Childhood eye diseases in Anambra State, Nigeria. Nigeria Journal of Ophthalmology. 1999;7:34-8.

2. Pratab VB, Lai HB. Pattern of pediatric ocular problem in North India. India J Ophthalmol. 1989;37:171-2.

3. Adegbehingbe $\mathrm{BO}$, Adeoye $\mathrm{AO}$, Onakpoya $\mathrm{OH}$. Refractive errors in childhood. Nigerian Journal of Surgical Sciences. 2005;15:19-25.

4. Narayana KM, Bora A, Biswas J. Pattern of uveitis in children presenting at a tertiary eye care centre in south India. India J Ophthalmol. 2003;52:129-32.

5. Gilbert C. Childhood Blindness In: Johnson G, Minassan D, Wealle R(eds) Epidemiology of Eye Diseases. London Chapmann and Hall. 1998:183-8.

6. King RA. Common ocular signs and symptoms in childhood. Pead Cli North Am. 1993;40:753-66.

7. Castenes MS. Major review: The underutilization of vision screening (for amblyopia, optical anomalies and strabismus) among preschool age children. Binocul Vis Strabismus Q. 2003;18:217-32.

8. Ajaiyeoba AA. Childhood eye disease in Ibadan. Afri J Med Sci. 1994;23:227-32.

9. Mohammed S, Abebe B Common eye diseases in children of rural community in Goro district, Central Ethiopia. Ethiopia J. Health Dev. 2005; 19:148-52.

10. Bodunde OT, Onabolu OO. Childhood eye diseases in Sagamu. Nigerian Journal of Ophthalmol. 2004;12:6-9.

11. Akinsola FB. Pattern of eye diseases in Nigerian children seen at Lagos University Teaching Hospital. Nigerian Medical Practitioner. 1993;25:47-53.

12. Ezegwui IR, Onwasigwe EN. Pattern of eye disease in children at Abakaliki, Nigeria. International Journal of Ophthalmology. 2005;5:1128-30.
13. Abiose A. Peadiatric ophthalmology problems in Lagos. Nigeria. J Trop Peadiatric. 1985;31:30-5

14. Isawunmi MA. Ocular disorders amongst school children in Ilesa east Local Government area, Osun State, Nigeria. National Postgraduate Medical College of Nigeria;Dissertation 2003.

15. Kuhn F, Morris R, Witherspoon D, Herman K, Jeffers JB, Trester G. A standard classification of ocular trauma. Ophthalmology. 1996;103:240-

16. Alhaski M, Almaaita J. Retrospective analysis of pediatric ocular trauma at Prince Ali Hospital. Middle East Journal of Family Medicine. 2007;5:42-5

17. Niiranem M, Ratvio I. Eye injuries in children. Br J Ophthalmol 1981; 65: 436-438.

18. World Health Organization. Prevention of Childhood Blindness In: Causes of Childhood blindness and current control measures. WHO Geneva.1992;21-22.

19. Olurin O. Eye injuries in Nigeria. A review of 433 cases. Am J Ophthalmol 1971;72: 159-66.

20. Nwosu SNN. Domestic ocular and adnexa injuries in Nigeria. W Afr J Med. 1995;14: 137-40.

21. Kwari F, AlHassan MB, Abiose A. Pattern and outcome of peadiatric ocular trauma - A 3- year review National Eye Centre Kaduna. Nigerian Journal of Ophthalmology. 2000;8:11-6.

22. Nkanga DG, Doln P. School vision screening in Enugu, Nigeria: Assesment of referral criteria for refractive error. Nigerian Journal of Ophthalmology. 1997;5:34-40.

23. Adeoye AO. Eye injuries in the young in Ile Ife, Nigeria. Nig J Med. 2002;11:26-28.

24. Starlman E, Elman M, Daub E, Baker S. Causes of peadiatric eye injuries. A population based study. Arch Ophthalmol. 1990;108:376-9. 
25. Wood M. Conjunctivitis: diagnosis and management. Community Eye Health Journal 1999;4:7-8.

26. Bekibele CO, Olusanya BA. Chronic Allergic Conjunctivitis: an Evaluation of Environmental Risk Factors. Asian Journal of Ophthalmol. 2006;8:147-50.

27. Majekodunmi S. Vernal conjunctivitis in Nigerian children. J Peadiat Ophthalmol Strabismus. 1978;15:176-8.
28. Yorston D. Mealses and childhood blindness. Community Eye Health Journal. 1991; 8:2-4.

29. Sandforth-smith JH, Whittle H. Corneal ulceration following measles in Nigerian children. Br J Ophthalmol. 1983;63:720-4.

30. Gilbert C. Childhood Blindness: Major causes and strategies for prevention. Community Eye Health Journal. 1993;11:3-6. 